\title{
RETURN MIGRATION AND RE-INTEGRATION OF RETURNEES CHALLENGES IN THE ORIGIN COUNTRY
}

\author{
Alkida Ndreka \\ University of Tirana, Albania \\ E-mail: alkidandreka@hotmail.com
}

Abstract: Return migration, traditionally not a well-studied and often neglected area, is becoming an important component of the international migration debate. Reintegration is an essential part of return migration and identified as a complex process that is experienced differently by returnees. The adaptation of immigrants in the host country has been extensively studied, while much less attention has been paid to economic and socio-cultural reintegration and the difficulties return migrants face once they come back to their homeland. Especially children and youth born in destination countries with sociolinguistic and socialization difficulties face a particularly tough reintegration process. Theoretically, there is comprehensive literature focused on return migration and reasons for return, but less in return migration policies and reintegration process. Empirically, there is a lack of studies focused on the reintegration of returnees, particularly in the socio-cultural aspect. With increased attention to the importance of this process, many states and governments have established policies or programs to encourage the return of their citizens, and facilitate returnees' successful and permanent relocation in the new society of the origin country. This paper aims to analyze theoretically and empirically the processes of reintegration of returnees in the origin country by identifying the challenges they encounter in the economic and social-cultural life of the origin country.

Key-words: return migration, second generation returnees, economic reintegration, socio-cultural reintegration, return migration policies.

\section{Introduction}

Migration in a globalizing world is an increasing phenomenon. People are looking for new opportunities and chances to improve their lives, since migration often is recognized as a 'route out of poverty' for many and a pathway to prosperity for some (King, Mata-Codesal and Vullnetari 2013, 74). The significant increase in international mobility is an outcome of the increased transportation links and the rapid growth in telecommunication 
technology. Migration is a dynamic and complex phenomenon, controlling and managing the movement of people worldwide is often challenging for states and governments. Particularly nowadays, most countries are not dominated by one type of migration, such as labour migration, family reunion, refugee movement or permanent settlement, but experience a whole range of types at once (Castles, de Haas and Miller 2014, 4). Migrants may move temporarily or permanently, individually or in groups, transnationally or nationally, return to their countries of origin or migrate to another country, or move between two or more countries.

Migration has gained increasing political salience over the past decades (Castles, de Haas and Miller 2014, 5), return migration, not a well-studied area, is becoming an important component of the international migration debate scene. Among scholars, the debate recognizes the positive contribution of returned migrants in poverty reduction, economic growth and sustainable development of the origin country. Returnees often bring significant benefits to their new communities in the form of skills, strengthening the labour force, investment and cultural diversity. They also play an important role in improving the lives of communities in their countries of origin through the transfer of skills and financial resources and taking up entrepreneurial activities in aid of their families and communities. In conclusion, there has been a growing recognition among policymakers that return migration is an indispensable part of a comprehensive approach to migration management, and that this can only be achieved through complementarity of efforts and coordination among State and non-State actors at both national and international levels (IOM 2018, 5).

\section{Why do migrants return? Return migration and typology of returnees.}

International experience shows that a majority of migrants return to their origin country. While data on international migration is more complete, data about return migration are missing and incomplete. On average an estimated two migrants in five will leave the host country within five years of arrival (Wahba 2015, 1); In Slovakia, on average each tenth person working abroad returned (Masso et al. 2016, 3), for regions such as Eastern Europe and Asia return migration may imply that 20 to 30 percent of highly educated emigrants return home when they are still productive and contribute importantly to the average income and wages of the sending country (Mayr and Peri 2008, 28); for the UK, Dustmann and Weis (2007) estimate out- 
migration rates of 40 percent for men and 55 percent for women after five years, using data from the 1990s (Dustmann and Weiss 2007, 253).

There are various reasons which encourage international migrants to leave the destination country. Not all international migrants will come back; some of them are having with them their families which are adapted in the new society. This category will not go back to the homeland. Another category of international migrants who will not return is the category of migrants who think about returning but they never act towards realizing it. The third category is the returnees, international migrants who leave the destination country urged by economic or non-economic reasons. The reasons which prompt return may vary from nostalgia for the homeland to return related to family ties or family reasons. Dumont and Spielvogel (2008) identify four main reasons to explain return migration: i) failure to integrate into the host country, ii) individuals' preferences for their home country; iii) achievement of a savings objective, or iv) the opening of employment opportunities in the home country thanks to experience acquired abroad (Dumont and Spielvogel 2008, 163).

Return migration is not an isolated phenomenon but it needs to be seen in the larger context of the international migration cycle of individual migrants, and in the context of migration management instruments applied by governments and states. Return migration can occur at different stages of the migration cycle, shortly after arrival in the destination country or many years later. No one can predict when the return will happen. There are different types of return, Marianne Haase and Pia Honerath (2016) identify four types: Involuntary return migrants; Return migrants whose return is "voluntary but unavoidable; Voluntary return migrants and Second-generation "quasireturnees". The first category refers to individuals with no legal residence status, whose economic and/or social integration failed, and who are deported back home (Haase and Honerath 2016,6). The second form of return might look voluntary, but is usually the inevitable consequence of failed migration and failed integration experiences in the host countries. The third are migrants that have an explicit intention to return, especially once they have reached their savings goals, or acquired skills, higher education or business networks in their host countries which they can transfer and apply back home. The fourth refers to second (or third)-generation diaspora members who wish to invest in the home country of their parents or grandparents (Haase and Honerath 2016, 7). Even though there are many types of return, the most preferred is voluntary return.

Many authors have contributed to the study of return migration by identifying different typologies of returnees like Gmelch (1980) and 
Bovenkerk (1974). One of the most frequently mentioned typologies of return migration is the one identified by Cerase (1974) distinguishing between four types of migrant returns: "Return of failure", "Return of Conservatism", "Return of Retirement" and "Return of Innovation" (Cerase 1974, 254). King (2000) suggests another typology of returned migrants by taking into consideration the length of the time spent back in the origin country: occasional returns, seasional returns, temporary returns and permanent returns (King 2000, 10-11). Recently Batistella (2018) use two variables: the time for return and the decision to return to identify four main types of return. Return of achievement: the migrant returns voluntarily at the end of the migration project (or contract) having achieved the purpose for which he or she went abroad. Return of completion: the migrant returns after completing the contract, but it is not a voluntary return, because the migrant would have liked to stay abroad for another period or to go abroad again; however, it is not possible. Return of setback: the migrant returns voluntarily but before the end of the migration process, for various reasons, including unhappiness at working conditions, family reasons, experience of abuse, or trafficking. Return of crisis (forced return): caused by situations like political upheaval or environmental disaster (Batistella 2018, 3-4).

There are many theories which explain the reasons affecting people to come back to their homeland. Jean-Pierre Cassarino (2004) identifies 5 theories which explain return migration in different perspectives. According to the Neoclassical Economics theory, return occurs as a consequence of their failed experiences abroad or because their human capital was not rewarded as expected (Cassarino 2004, 255). This theory states that return is perceived as a failure; New Economics of Labour Migration (NELM) views return migration as the logical outcome of a "calculated strategy", defined at the level of the migrant's household, and resulting from the successful achievement of goals or target (Cassarino 2004, 255). The focus of a third theory, Structural Approach, is on the extent to which returnees may or may not have an impact on their origin societies once return takes place (Cassarino 2004, 259). According to transnationalism approach, returnees prepare their reintegration at home through periodical and regular visits to their home countries. They retain strong links with their home countries and periodically send remittances to their households (Cassarino 2004, 262).

Social Network Theory views returnees as migrants who maintain strong linkages with their former places of settlement in other countries (Cassarino $2004,265)$. According to this theory social networks created and shaped during the migration period are beneficial in the origin country by enriching migrants with resources and information. Similar to transnationalism, even 
Social Network Theory does not consider return migration as the end of the migratory process.

Return migration has, in recent decades, emerged as a critical element of many governments' migration policy - an integral part of effective migration management. According to Lesińska (2013), the state's policy towards return migration could take two forms: a more active or more passive form.

- 1.: A reactive state policy is implemented post factum, i.e. as a response to the already existing processes. Commonly, returns are a direct effect of an economic crisis in destination countries followed by growing unemployment, when migrants usually decide to return to live through the difficult time at home.

- 2.: An active state policy is executed $a$ priori, i.e. to encourage nationals to return. When returns are recognized as a positive and desirable process (as a remedy for particular economic or social problems), then policy-makers act to stimulate migrants' decision to return and to facilitate the process of coming back to the home country (Lesińska 2013, 79).

Many governments, especially from less developed regions, have instituted policies or programs to encourage the return of their citizens. Globally, 72 percent of governments have policies to encourage the return of their citizens. The share of governments seeking to encourage the return of their citizens is highest in Latin America and the Caribbean (88 percent), followed by Africa (78 percent) (United Nations 2017, 8). Furthermore, some governments have also established dedicated agencies or ministries, research hubs and centres, and virtual databases and networks to connect potential returnees with opportunities in the countries of origin (Debnath 2016, 10). States benefit from the return of migrants since they have positive impacts for the development of countries of origin through capital inflows, investments and the transfer of technologies and skills.

As migration becomes more complex, there is also an increasing need for international brokering of cooperative approaches between origin, transit and destination countries. International Organization of Migration (IOM) has established some multilateral programs to foster effective partnerships on return migration. IOM through its programs is helping and supporting different categories of returnees. IOM is playing a crucial role with its Assistance and Reintegration Programs (AVRR). At the beginning of these programs they were providing support bases for facilitating the issue of transport return, but with time it has evolved into more comprehensive programs to integrate a range of services to promote sustainability of return. IOM operates through three types of AVR programmes: a) General return assistance for irregular migrants, unsuccessful asylum seekers, refugees and 
others wishing to return from the host country; b) Specific return and reintegration assistance tailored to the needs of certain groups (e.g. nationality, vulnerable groups, skilled and qualified nationals); c) Assistance to migrants stranded en route (IOM 2008, 2). These programmes enhanced return counselling, information services and reintegration support for the returnees.

\section{Theoretical Approach on Reintegration}

A developing trend in academic literature starts to conceptualize return migration and reintegration as broad processes dependent upon various aspects and actors instead of the simple journey of "returning home". Consequently, also more and more attention is paid to the difficulties reintegration processes bring with them, which often are manifold and increasingly complex (Gomilkó et al. 2015, 14-15). While the situation of immigrants has been extensively studied, much less attention has been paid to the difficulties return migrants face when they come back to live in their countries of birth. This relative lack of research may be based on a view that once immigrants have returned to their home country, they blend back in and are then essentially no different to other natives in that country of origin (Barrett and Mosca 2012, 2).

IOM in the Glossary of migration defines reintegration as a "re-inclusion or re-incorporation of a person into a group or a process, e.g. of a migrant into the society of his or her country of origin or habitual residence "(IOM 2011, 82). But beyond this definition, IOM identifies three fields as crucial aspects for a returnee to readapt in the new society. One of these fields is the economic reintegration which is defined as "the process by which a migrant is reinserted into the economic system of his or her country of origin, and able to earn his or her own living.

Returnees' employment and integration into the labour market are crucial elements in their reintegration into the origin society. Economic reintegration is important not only because it provides the income for the household, but the lack of income affects the wellbeing of the returnees. Having a job has constantly been identified as a major factor to positively influence many issues related to the psychological well-being and the social integration of returnees such as: reestablishing self-esteem and confidence, engaging with social networks and community and improving of the language and social skills with non-migrants in the origin country. In addition, the origin country may profit by experience and the skills of returnees acquired in the foreign country. Despite its importance, returnees are faced with certain challenges 
regarding their economic reintegration such as: lack of employment in the origin county, differences in labour market between host and origin countries, lower wages comparing to their abilities and experience the skills of the return migrant may not be well matched to the economy of the origin country, lack of networks helping to find a job, limited economic opportunities upon return etc.

The second aspect is the social reintegration which is defined as "the reinsertion of a migrant into the social structures of his or her country of origin. This includes on the one hand the development of a personal network (friends, relatives, neighbours) and on the other hand the development of civil society structures (associations, self-help groups and other organizations)" (IOM 2011, 82). Social ties to the home country during the stay abroad seem to be of great relevance for the process of return and reintegration. Migrants stay in contact with friends and family at home and those contacts can be pullfactors for return migration. The social networks play a paramount role in informing about socio-economic and political conditions of the origin country and a support and facilitator in the return and reintegration process. They are a central tool in welcoming returnees back into the community, providing them with information and social capital, helping in finding a job or in starting a new business and in the provision of housing. Next to the more material function, social relations appeared to be crucial in the overall well-being and emotional needs of returnees (Kuyper 2008, 18).

On the one side, for many returnees, having established good social networks in the origin country is important to facilitate their reintegration but to the other side, returnees often face challenges when they try to (re)create social relationships and networks that may be useful for their economic, social or political activities in the country of return (Åkesson and Eriksson-Baaz 2015, 13).

The third field of reintegration is focused on the cultural aspect, in the context of return migration, it refers to the "re-adoption on the part of the sets the reintegration into three aspects, cultural, ecological and social returning migrant of the values, way of living, language, moral principles, ideology, and traditions of the country of origin's society" (IOM 2011, 82). It is true that migrants are coming back to their homeland but during their absence a lot has changed, tone of the reasons why the reintegration of returned migrants in their country of origin is a tough process (Chobanyan 2013, 7). Return migrants are back in their own culture, they know the language, and they are not foreigners. They recreate new networks or keep in touch with old friends but during the time that they have "been away" many socio-cultural aspects of the origin country have changed and for more there is a difference between 
the society, norms, values and lifestyle of the destination and origin country. While for some migrants the cultural reintegration happens gradually and without any issue, for some others it is a very difficult process. Markowitz and Stefansson (2004) highlight that the return migrant might face a cultural shock on the homecoming and thus, return is experienced as a culture shock, a trauma or a new displacement, whereby returnees become alienated from their homeland (Markowitz and Stefansson 2004, 10).

Just the process of returning is not enough but the return needs to be permanent and sustainable, otherwise return may be just one part of the migration cycle. Koser (2015) defines 'sustainable return' as when: 'The individual has reintegrated into the economic, social and cultural processes of the country of origin and feels that they are in an environment of safety and security upon return' (Koser 2015, 3). According to this definition, reintegration is a necessary precondition for meaningful sustainable return and it also highlights that the returnee must perceive that they are in conditions of safety and security upon return.

In the process of reintegration, the supportive mechanisms like return policies, social networks and families have a key role in facilitating, informing and supporting returnees and contributing to the sustainability of return. Kuschminder (2017) identifies 4 types of reintegration strategies for returnees and specifies characteristics of each type describing many variables. The reintegration strategies are not permanent and return migrants may adopt different strategies at different stages of their return.

The first strategy is named 'reintegrated', these returnees have been abroad for a longer duration (more than five years), has a high preparedness for return, and possesses skills or a comfortable level of wealth (Kuschminder $2017,46)$. They identify themselves as being transnational and have a strong access to the labour market due to their skills and adaptability. The second strategy is 'enclave' strategy. Return migrants in the enclave strategy are similar to those in the reintegrated strategy in that they have been abroad for a longer duration (more than five years), have a high preparedness for return, and possesses skills or a comfortable level of wealth (Kuschminder 2017,46). They maintain the culture of the country of migration and do not adapt to the local culture, and the social network of the enclavists is primarily comprised of other returnees. The third strategy is the 'traditionalist'. The traditionalist typically has been abroad for a shorter amount of time (3-5 years), has a medium level of preparedness for return, and had less social status than the enclavists or reintegrated. The traditionalist has fully adapted to the local culture and rejects the culture of the country of migration (Kuschminder $2017,46)$. The traditionalists' social network is primarily comprised of locals 
with minimal to no interaction with other return migrants and the crossborder networks from the country of migration. The final reintegration strategy is the 'vulnerable'. The vulnerable have been abroad for a shorter duration (less than 2 years), have a low preparedness for return, and often are low skilled with low social status. The vulnerable generally have had an unsuccessful migration experience and may have been forcibly returned as a deportee (Kuschminder 2017, 47). They do not associate with the culture of the country of migration and are often rejected by the dominant culture in the country of origin.

\section{Empirical Studies on Reintegration of Return Migrants}

The focus of the studies on return migration is varied, like intentions to return, reasons for returning back, some other scholars have been studying the reintegration process which takes place after the return. These studies try to expose a panorama of the reintegration process, including difficulties and challenges faced by returnees. In this context, they may be used by governments and states to draft and implement successful return and reintegration policies. While the reintegration process is multidimensional, an important and most studied topic in empirical studies is economic reintegration. This is due to the fact that returnees are generally perceived as individuals bringing skills and innovation to their homeland; and their economic success is not only the effect in the household income but the important economic implications in the development of the origin country. The economic reintegration of returnees is not always easy; returnees often face challenges in finding a job, lower wages, etc.

The economic reintegration studies are mostly focused on two areas: entrepreneurial activity among returnees and studies that compare the wage paid of returnees with non-migrants. The findings vary considerably from study to study. Barrett and Goggin (2010) in Ireland found a significant wage premium for returned migrants relative to stayers at each educational level. Returnees who possess a postgraduate qualification earn a 10 percent wage premium relative to stayers with postgraduate qualifications (Barrett and Goggin 2010, 9). In another study in Ireland, Barrett and O'Connell (2001) showed that among graduates of Irish colleges, returning males do indeed earn more than males who stayed in Ireland although no effect is found for returning women (Barrett and O'Connell 2001,19).

Rooth and Saarela (2007) in Finland found that return migrants have over 10 percent higher unstandardised earnings than those who stay in the host country (Rooth and Saarela 2007, 93). Co, Gang and Myeong (2000), in 
Hungary found there was a large wage premium (40 percent) for returning migrant women in Hungary but found none for men. According to this study, the time spent abroad improves the labour market performance for female migrants but not for male migrants. Gender differences in payment are even found by Hazans (2008), after controlling for worker demographic characteristics and education, as well as foreign experience and unemployment experience of family members, return migrants command a substantial earnings' premium: about $15 \%$ on average, more than $20 \%$ among men, and 6\% among women (Hazans 2008, 24). Di Cintio and Grassi (2016) in Italy studied migrants and non-migrants who have a Ph.D. The study revealed that migrants earn around $3.7 \%$ more than non-migrants. Conversely, those who choose to remain abroad for longer periods seem to enjoy increasing wage gains. On average, duration between one and two years is associated with a $7.5 \%$ higher wage, a duration between two and three years with a $13.2 \%$ increase and a duration of at least four years with a 27\%increase (Di Cintio and Grassi 2016, 11). Masso et al (2016) analysed return migration of young people (15-34 years). Estonian returnees reap benefits in terms of higher wages, but no evidence was found of a positive effect of migration and return on the upward occupational mobility of the returnees (Masso et al. 2016, 3).

Some studies focus on difficulties of returnees in finding a job in the origin country after their return. Abarcar (2016) studying the Filipino labour market of returnees, demonstrates that employers do not favour return migrants when similar workers with the same set of skills and educational background are available. He explains that the following factors play at best a minor role: First, that employers perceive return migration to be a negative signal, indicating negative selection into migration or failure abroad; second, that employers believe return migrants demand high wages; third, that employers think return migrants are overqualified; and fourth, that employers believe return migrants have high job turnover rates. A fifth possible explanation, the depreciation of location-specific human capital, appears most plausible (Abarcar 2016, 2).

Some other returnees have experienced different difficulties once they have returned. Connell (2009) studied the return of skilled workers, doctors and nurses who have returned to the island of Pacific, Samoa, Tonga and Fiji. Many migrants find return difficult, facing lower wages and standards of living, difficulty in establishing businesses and, simply, culture shock (Connell 2009, 74). Van Meeteren, Engbersen, Snel and Faber (2014) studied different post-return experience of returnees in Morocco and identified three types of experiences; while the first group was well-prepared and generally reported 
no difficulties, the second group was moderately prepared and reported some difficulties, especially in the beginning of their return. The third group reported a lot of difficulties, especially in coping with failed migration experiences and because they had made practically no preparations for their return (Van Meeteren et al. 2014, 355). Setrana (2017) studying returnees in Ghana found that the result indicates that returnees who are satisfied about their return are more likely (130 percent) to successfully reintegrate than those who are not satisfied about their return. In other words, reintegration is easily achieved when returnees are satisfied with their situation upon return, even in the midst of challenges and vice versa (Setrana 2017,40).

Some studies focus on the sector of the labour market in which returnees are more engaged. Kupets (2011) analyses the labour market of returned migrants in Ukraine by specifying types of economic activity and occupations dominated by returned migrants compared to non-migrants. The most common occupations by returnees belong to the following four occupational groups: craft and related workers, elementary occupations, service workers and shop and market sales, and plant and machine operators and assemblers (with a large share only in the formal sector) (Kupets 2011,23). Arif and Irfan (1997) investigate issues related to the professional change of returning migrants to Pakistan. The authors noted the tendency of Pakistani emigrants to change the profession after returning and switching to self-employment by creating businesses and farms. The result showed that among the employed, 44 percent, changed their pre-migration occupations upon return, mainly from production-service occupation to small businesses (Arif and Irfan 1997, 27). Ilahi (1999) in Pakistan, return migrants exhibit a high tendency for selfemployment over waged employment. Upon return, savings become a significant factor in the choice of self-employment over waged employment (Ilahi 1999, 170).

Many empirical studies have yielded consensus on the positive relationship between return migration and entrepreneurial activity. These enterprises can be significant contributors to economic growth and alleviating poverty by creating jobs, employment and increasing income for households. Many research studies suggest that returnees have higher probability to be engaged to entrepreneurial activity comparing to the people who never migrate. McCormick and Wahba (2001) found that both overseas savings, and the duration of stay overseas increase the probability of becoming an entrepreneur amongst literate returnees to Egypt (McCormick and Wahba 2001, 16). Dustmann and Kirchkamp (2002) studying returnees to Egypt conclude that most of them engage in entrepreneurial activities (Dustmann and Kirchkamp 2002, 351); while Wahba and Zenou (2009) find 
that returnees are more likely than non-migrants (11\%) to become entrepreneurs (Wahba and Zenou 2009, 21); Batista, McIndoe-Calder \& Vicente (2014) study in Mozambique shows that being a return migrant is associated with a significant increase of 13 percentage points in the probability of owning a business relative to non-migrants (Batista et al. 2014, 25); Marchetta (2012) provides evidence of high propensity of returnees to engage in entrepreneurial activities and econometric analysis evidences the fact that returnees have a significantly higher probability to survive over time as entrepreneurs if compared to stayers (Marchetta 2012, 23).

There is a lack of empirical studies focusing on cultural reintegration. Setrana and Tonah (2014) studying returnees in Ghana, found that returnees faced cultural difficulties once they came back to their homeland. Return migrants often have to regain an understanding of how local structures work at home, and often face a period of adaptation due to prolonged time spent abroad, during which a realistic picture of the home context may be lost. Some of the major factors that obstruct the return migrants' ability to induce change include poor local work ethic, poor working conditions, lack of adequate and modern infrastructure as well as a slow bureaucracy characterized by corruption (Setrana and Tonah 2014,137). Similar results have been found by Mercier, David, Mahia, and De Arce (2016) studying Ecuadorian return migrants from Spain who have experienced significant cultural interactions with their host society. The returnees who embraced many aspects of the host culture subsequently experience difficulties to reintegrate in their origin country and to interact with the home culture (Mercier et al. 2016).

Another group of researchers has analyzed the social reintegration of returns by identifying returnees' experiences and highlighting the important role of family and social networks as emotional and material support for them.

Kuyper (2008) studied returnees in Vietnam and found that the majority of returnees experienced a negative change in their social relations compared to before they left Vietnam. They experienced a lack of understanding about their return from the side of family, friends, neighbours and people in the community (Kuyper 2008, 19).

There are studies focused on family, social networks and their impact on returnees' life. They are perceived as a support mechanism for the returnees, helping them in different aspects like finding a job, house or emotional support. In Armenia, Fleischer (2008) found that after return, more than half of the sample (54\%) received support and assistance from their family. Family members provided psychological and moral support (48\%), gave returnees an update in the current situation (41\%), (re)established 
contacts/networks (29\%) and/or assisted in the search for employment (21\%) (Fleischer 2008, 11). Another study in Armenia, Chobanyan (2013) found that after return, the family was of great support to the returnees interviewed, both financially and emotionally (Chobanyan 2013,9).

Social networks and family help and support the reintegration of not only the first generation but also the second generation. Reynolds (2008) studying the return of the second generation in the Caribbean, found that family supported their reintegration by assisting them with practical details of the return such as the building and purchasing of homes, finding work and other employment opportunities, and information concerning duty and tax concessions (Reynolds 2008, 19).

Similar results were found also by Paasche (2016) in studying the return of Iraqi Kurds from Europe, and Crescenzi et al (2016) analyzing returnees to Sardinia (Italy).

Beyond the above-mentioned studies, some other researchers and studies have shown that returnees have experienced mental health issues. Birara (2017) revealed that hopelessness, social isolation and development of low self-esteem prevail in the Saudi Arabian returnees (Birara 2017, 36). While Barrett and Mosca (2012) found feelings of disappointment, isolation, alienation and not belonging among returnees (Barrett and Mosca 2012, 4).

\section{Children and Youth in Return Contexts}

Within migration studies, with few exceptions, children and youth as a group only recently have 'become visible' (Hunner-Kreisel and Bohne 2016,4). They have remained outside the focus of migration researchers for a long time, but as migration increases around the world, their interest in the role of migration in children's and youth's well-being is growing. Migration phenomenon affects them either if they migrate together with their families, or if they stay behind with their relatives or acquaintances in the homeland.

In sociological studies, the return of children or youth to the homeland of their parents is known as return of 'second generation'. They may have left the origin country in their early years or even been born in the destination country. Second generation individuals returning to their parents' country of origin actually move to a country where they were not born and raised in. The "second generation" is not a homogenous group and challenges may be more severe for some children and youth than for others. Children and youth with no experience in their parents' homeland often have problems adjusting to their new location and dealing with issues of identity and belonging. Being born and raised in a different society and culture requires adaptation to the 
new environment. The process of socialization is often disrupted as it requires the adoption of norms and values which are often different from those of the destination country where the children were born. Educational integration is of crucial importance for returning children and youth. This is due to an unequal start resulting from the need to adapt to the system and the educational environment, as well as language barriers, which in turn affect the children's educational achievements. They have to adjust to the new educational system in which the content, teachers' attitudes and teaching methods differ from those they are used to. Still, for the children, the return journey and attempts of reintegration can often be overwhelming, especially if they have spent significant parts of their lives (or even were born and raised) in host countries. Since adults are almost never immune against a possible 'return shock', there is an additional special need for children to enjoy the return and reintegration phases without or only limited psychosocial unrest and trauma (Gomilkó et al. 2015, 17-18).

There are some empirical studies which have analysed the children and youth returning to the parents' origin country and the problems of adaptation both in the educational system and in the psycho-social aspect.

Lepore (1986) found that migrant children commonly face problems related to education because of differences between languages, teaching content, and educational methods practiced in the two countries. Kilinc (2014) studying the return of second-generation Turk-Germans to the parents homeland, found that adolescents who came back with their parents had difficulties adapting to the Turkish educational system as well as communication difficulties with people in Turkey. Similar results were also found by Terlikbayeva (2017) studying children returning to Kazakhstan. Li, Zhu and Zuo (2019) empirically estimated the impact of return migration on the mental health of children. The results showed that the experience of return migration has a significant negative impact on children's mental health as measured by depression risk, self-esteem and resilience. Vathi and Duci (2016) found similar results in Albania. The study showed that migration at a young age, even as part of a family's return to their country of origin, can negatively affect children's and young people's psychosocial wellbeing (Vathi and Duci 2016,63). Second generation children who returned to Japan, who had little exposure to Japanese culture, are described by Fry (2009) as "educational refugees and were regarded as culturally ambiguous, socially marginalized and academically marginalized". Yehuda-Sternfeld and Mirsky (2014) found that the second generation of Israeli-Americans who returned to Israel was surprised and disappointed that they encountered difficulties, 
and felt and were treated as strangers (Yehuda-Sternfeld and Mirsky 2014, 61).

\section{Conclusion}

Worldwide, the number of international migrants is increasing each year; consequently, the movement affects people, the origin country, the destination country and state policies. International return migrants have received increase attention due to the fact that many states are facing the intensifying numbers of returnees and flows of refugees. Hence, there is a need to manage the movements and mitigate the negative consequences associated with it. Even though the focus of this paper is voluntary return, and it is the most preferable alternative, it becomes evident that states face even involuntary return of different categories. International migrants who decide to leave the destination country and return to their homeland are motivated by personal, familiar and economic reasons. The migration experience can be stressful, and so is return migration which can negatively impact the returnees in many aspects: economically, socially and psychologically. The reintegration experiences of return migrants in their home countries have received some attention in the sociological literature, theoretically and empirically. Even though returnees are often faced with difficulties in finding a job because of the local labour market, empirical studies identify that once they are employed; their payment is higher than non-migrants. Also many empirical studies have yielded consensus on the positive relationship between returnees and engagement in entrepreneurial activity. These enterprises are significant contributors to economic growth and alleviating poverty by creating jobs, employment and increasing income for households.

From the social aspect of reintegration, returnees often lack access to networks and friends. They find it difficult to build up new social relations again. Friends and network have a crucial role in facilitating the reintegration process of returnees especially when they first come back. Their support includes finding a job, a house and even emotional support. Some empirical studies have highlighted the feeling of frustration, isolation, and feelings of alienation among returnees. Children and youth who come back to their origin country or that of their parents' face challenges in different aspects; language problems especially for the children and youth born in the destination country, difficulties in the school environment, lack of socialization and mental health issues.

State policies of reintegration play an important role in supporting the returnees and facilitating their social and economic reintegration. The state 
can benefit from the returnees and their skills by facilitating the creation of entrepreneurial activities. This policy helps returnees and their family in reintegrating and also creates jobs for non-migrants, helping in the economic growth and prosperity of the country.

\section{References}

Abarcar, Paolo. 2016. Do Employers Value Return Migrants? An Experiment on the Returns to Foreign Work Experience. Working Paper 48, Mathematica Policy Research.

Åkesson, Lisa, and Maria Eriksson-Baaz, eds. 2015. Africa's Return Migrants: The New Developers? London: Zed Books, 192.

Arif, M. Ghulam and Mohammad Irfan. 1997. "Return Migration and Occupational Change: The Case of Pakistani Migrants Returned from the Middle East." The Pakistan Development Review 36 (1): 1-37.

Barrett, Alan and Jean Goggin. 2010. Returning to the Question of a Wage Premium for Returning Migrants. Discussion Paper No. 4736, IZA.

Barrett, Alan and Philip J. O'Connell, 2001. "Is There a Wage Premium for Returning Irish Migrants." Economic and Social Review 32 (1): 1-21.

Barrett, Alan and Irene Mosca. 2012. Social Isolation, Loneliness and Return Migration: Evidence from Older Irish Adults. IZA DP, No. 6331.

Batistella, Graziano. 2018. Return Migration: A Conceptual and Policy Framework. Scalabrini Migration Center.

Batista, Catia, Tara McIndoe-Calder, and Pedro C. Vicente. 2014. Return Migration, Self-Selection and Entrepreneurship in Mozambique. IZA DP No. 8195.

Birara, Desalegn. 2013. "Challenges of Social Reintegration for the Saudi Arabian Returnees in Ethiopia." International Journal of Humanities and Social Science Research 3: 31-37.

Boatemaa Setrana, Mary and Steve Tonah. 2014. Do transnational links matter after return? Labour market participation among Ghanaian return migrants! 
ECAS 2013 5th European Conference on African Studies African Dynamics in a Multipolar World(C2014 Centro de Estudos Internacionais do Instituto Universitário de Lisboa (ISCTE-IUL) ISBN: 978-989-732-364-5.

Bovenkerk, Frank. 1974. The Sociology of Return Migration: a Bibliographic Essay.

Cassarino, Jean-Pierre. 2004. "The Conditions of Modern Return Migrants." International Journal on Multicultural Societies (IJMS) 10 (2).

Castles, Stephen, Hein de Haas, and Mark J. Miller. 2014. The Age of Migration, International Population Movements in the Modern World, Fifth Edition.

Cerase, P. Francesco. 1974. "Expectations and reality: a case study of return migration from the United States to Southern Italy." International Migration Review 8 (2): 245-62.

Chobanyan, Haykanush. 2013. Return Migration and Reintegration Issues: Armenia, CARIM-East Research Report 2013/03. Research Report CARIMEast RR 2013/03. European University Institute Robert Schuman Centre for Advanced Studies.

Co, Catherine Y, Ira N. Gang, and Yun Myeong-Su. 2000. "Returns to Returning." Journal of Population Economics 13 (1): 57-79.

Connell, John. 2009. I Never Wanted to Come Home': Skilled Health Workers in the South Pacific. Migration and Transnationalism, Pacific Perspectives, ANU Press.

Crescenzi, Riccardo, Nancy Holman, and Enrico Orru. 2016. "Why do they return? Beyond the economic drivers of graduate return migration." Annals of Regional Science. ISSN 1432-0592. DOI: 10.1007/s00168-016-0762-9.

Debnath, Priyanka. 2016. Leveraging Return Migration for Development: The Role of Countries of Origin. A Literature Review. Global Knowledge Partnership on Migration and Development (Knomad), Knomad Working Paper 17.

Di Cintio, Marco and Emanuele Grassi. 2016. The returns to temporary migration: The case of Italian Ph.D.s. EERI Research Paper Series No 15. 
Dumont, Jean-Christophe and Gilles Spielvogel. 2008. Return Migration: A New Perspective. International Migration Outlook SOPEMI - 2008 Edition, OECD.

Dustmann, Christian and Yoram Weis. 2009. "Return Migration: Theory and Empirical Evidence from the UK." British Journal of Industrial Relations 45 (2): 236-256.

Dustmann, Christian, and Oliver Kirchkamp. 2002. "The optimal migration duration and activity choice after re-migration." Journal of Development Economics 67: 351 - 372.

Fleischer, Annett. 2008. The role of the family for return migration, reintegration and re-emigration in Armenia. XXVII IUSSP International Population Conference. Accessed http://www.iussp.org/en/event/17/programme/paper/2411.

Fry, Rieko. 2009. "Politics of education for Japanese returnee children." Compare 39 (3): 367-383. Doi:10.1080/03057920701712908.

Haase, Marianne and Pia Honerath. 2016. Return Migration and Reintegration Policies: A primer. Deutsche Gesellschaft für Internationale Zusammenarbeit (GIZ) GmbH + German Marshall Fund of the United States.

Hazans, Mihails. 2008. Effect of foreign Experience on Return Migrants' Earnings: Causality and Heterogeneity. Manuscript, University of Latvia.

Hooper, Kate and Madeleine Sumption. 2016. Reaching a "Fair Deal" on Talent Emigration, Circulation, and Human Capital in Countries of Origin. Migration Policy Institute.

Hunner-Kreisel, Christine and Sabine Bohne, eds. 2016. Childhood, Youth and Migration. Connecting Global and Local Perspectives. Springer International Publishing Switzerland.

International Organization for Migration (IOM). 2008. Assisted Voluntary Return (AVR). Geneva.

International Organization for Migration (IOM). 2018. A Framework For Assisted Voluntary Return And Reintegration. 
King, Russell. 2000. Generalisations from the history of return migration. In Return Migration: Journey of Hope or Despair?, edited by B. Ghosh, 7-55. Geneva: IOM and UN.

King, Russell, Diana Mata-Codesal, and Julie Vullnetari. 2013. "Migration, Development, Gender and the 'Black Box' of Remittances: Comparative Findings from Albania and Ecuador." Comparative Migration Studies 1 (1): 6996. Doi: 10.5117/Cms2013.1.King.

Kilinc, Nilay. 2014. Second-Generation Turkish-Germans Return 'Home': Gendered Narratives of (Re-) negotiated Identities. Working Paper No. 78. Sussex Centre for Migration Research.

Koser, Khalid. 2015. Promoting the Assisted Voluntary Return and Reintegration of Migrants. Research Programme, Occasional Paper Series No. 16.

Kuyper, Machteld. 2008. Return Migration to Vietnam, Monitoring the Embeddedness of Returnees. Nijmegen.

Kupets, Olga. 2011. Brain Gain or Brain Waste? The Performance of Return Labor Migrants in the Ukrainian Labor Market. Working Paper No 11/06e.

Kuschminder, Katie. 2017. Reintegration Strategies, Migration, Diasporas and Citizenship. DOI 10.1007/978-3-319-55741-0_2.

Lepore, Silvia. 1986. "Problems confronting migrants and members of their families when they return to their country of origin." Int Migr 24 (1): 95-112.

Lesińska, Magdalena. 2013. The Dilemmas of Policy Towards Return Migration. The Case of Poland After the EU Accession. Central and Eastern European Migration Review 2 (1): 77-90.

$\mathrm{Li}$, Xu, Zhisheng Zhu, and Hong Zuo. 2019. “The impact of return migration on the mental health of children." Applied Economics Letters 26 (3): 217-221.

Markowitz, Fran and Anders H. Steffanson, eds. 2004. Homecomings: unsettling paths of return. Maryland: Lexington Books. 
Marchetta, Francesca. 2012. "Return migration and the survival of entrepreneurial activities in Egypt.” World Development 40 (10): 1999-2013.

Masso, Jaan, Lucia Mýtna Kureková, Maryna Tverdostup, and Zuzana Žilinčíková. 2016. Return migration patterns of young return migrants after the crisis in the CEE countries: Estonia and Slovakia. Strategic Transitions for youth labour in Europe.

Mayr, Karin and Giovanni Peri. 2008. Return Migration as Channel of Brain Gain. CReAM Discussion Paper No 04/08.

McCormick, Barry, and Jackline Wahba. 2001. Overseas Work Experience, Savings and Entrepreneurship Amongst Return Migrants to LDCs. Scottish Journal of Political Economy 48 (2). 164-178.

Mercier, Marion, David Anda, Mahia Ramon, and Rafael De Arce. 2016. Reintegration upon return: insights from Ecuadorian returnees from Spain. DOCUMENT DE TRAVAIL DT/2016-04.

Nadeem, Ilahi. 1999. "Return Migration and Occupational Change." Review of Development Economics 3 (2): 170-186.

Paasche, Erlend. 2016. "The role of corruption in reintegration: experiences of Iraqi Kurds upon return from Europe." Journal of Ethnic and Migration Studies 42 (7): 1076-1093. DOI: 10.1080/1369183X.2016.1139445.

Perruchoud, Richard and Jillyann Redpath-Cross, eds. 2011. Glossary on Migration, $2^{\text {nd }}$ edition, IOM.

Reynolds, Tracey. 2008. Ties That Bind: Families, Social Capital and Caribbean Second-Generation. Return Migration Families \& Social Capital Research Group Working Paper No. 23.

Rooth Dan-Olof and Jan Saarela. 2007. "Selection in migration and return migration: Evidence from micro data." Economics Letters 94: 90-95.

Setrana Boatemaa, Mary. 2017. "Back Home at Last! Factors Influencing Return and Reintegration of Ghanaian Returnees." Journal of Identity and Migration Studies 11 (1). 
Terlikbayeva, Nurgul. 2017. "Integration of returnee children in Kazakhstani schools." NUGSE Research in Education 2 (1): 2-11.

United Nations. 2017. International Migration Policies: Data Booklet (ST/ESA/ SER.A/395).

Van Meeteren, Masja, Godfried Engbersen, Erik Snel, and Marije Faber. 2014. Understanding Different Post-Return Experiences. The Role of Preparedness, Return Motives and Family Expectations for Returned Migrants in Morocco, Vol. 2, no. 3 .

Vathi, Zana and Veronika Duci. 2016. "Making other dreams: The impact of migration on the psychosocial wellbeing of Albanian-origin children and young people upon their families' return to Albania." Childhood 23 (1): 5368: SAGE.

Wahba, Jackline. 2015. Who benefits from return migration to developing countries. University of Southampton, UK, and IZA, German. Doi: 10.15185/izawol.123.

Wahba, Jackline and Yves Zenou. 2009. Out of Sight, Out of Mind: Migration, Entrepreneurship and Social Capital. Discussion Paper No. 4541.

Yehuda-Sternfeld, S. Ben and Julia Mirsky. 2014. "Return migration of Americans: Personal narratives and psychological perspectives." International Journal of Intercultural Relations 4: 53-64. 